Original article

\title{
EVALUATION OF THE STONE ARTIFACTS EXHIBITION STATUS, IN THE NUBIAN MUSEUM GARDEN, ASWAN, EGYPT, A CASE STUDY.
}

\author{
Atef A. Brania \\ Assoc. Prof. Department of Egyptology, Faculty of Archaeology, Cairo University, Egypt \\ atefbran@yahoo.com
}

\begin{abstract}
Museums need to maintain appropriate and stable environment for protection and preservation their collection. Conditions in exhibition, storage and garden areas need monitoring and modification wherever possible to ensure safety and preservation of the museum collection. Because of its high durability against the different deterioration factors, the stone artifacts in the museum gardens are so common. The aim of this paper is to highlight on the stone artifacts, which are displaying in the Nubian museum garden in Aswan city, to evaluate the current exhibition status. Collecting information about the museum garden environment and Aswan city studied. Samples from a selected stone relief's investigated and analyzed by using XRD, SEM (EDAX), LOM and FTIR, for evaluation of the status. Recommendations for the stone relief's exhibition in the Nubian museum garden presented.
\end{abstract}

Keywords: Stone artifacts, Museum garden, XRD, SEM-EDAX, LOM, and FTIR.

1. Introduction "Aswan and the Nubian Museum "

Aswan stands on the east bank of the

Nile south of Egypt and far $879 \mathrm{~km}$ from Cairo, with geographical coordinates $24^{\circ}$ 5' 15" north, 32 53 ' 56" east. It formerly spelled Assuan, (Arabic: "أسوان Aswan", ancient Egyptian: "Swenet trade",

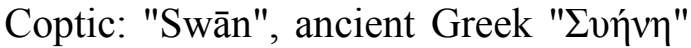
Syene is a city in the south of Egypt ,the capital of the Aswan governorate now)., [1][2][3].The Nubian Museum in Aswan is the one of most recent museum that has been built with the cooperation between UNESCO and the Egyptian government. It is gained a unique position, simply because it harbors unique monuments not in any elsewhere. The history of the museum started in the early 1960's, when Egypt built the high dam at Aswan, Egyptologists and archaeologists of the world over heeded UNESCO's appeal to salvage the monuments of Egyptian Nubia before the rising waters of Lake Nasser submerged them forever. More than sixty expeditions ultimately joined the Nubian rescue campaign, which resulted in the excavation and recording of hundreds of sites, the recovery of thousands of objects, and the salvage and translocation of a number of important temples to higher ground. Due to the quantities of material recovered from tombs, temples and settlements, UNESCO was encouraged in the 1980's to plan a new Nubian museum in Aswan where the objects could be stored and exhibited. It was universally felt at the time that they should be kept as close as 
possible to their principal places of origin. Nearly twelve years later; the Museum became a reality and opened its doors in November 1997. It was designed by the late Egyptian architect Mahmoud al-Hakim, and Mexican architect Pedro Vasquez Ramirez designed the museum's interior display. The site which was selected for the museum is ideal with respect to both environmental considerations and its location in Aswan [4][5]. It is situated in the neighborhood of hotels overlooking the town. It is, at the same time, close to the river Nile, facing Elephantine Island and the western bank, fig.(1). The total area of the complex is 50,000 square meters: 7,000 allocated for the building, and 43,000 for the grounds, fig. $(2,3)$. The building is set within a landscape, on graded levels, that includes a sequence of waterfalls. The remaining

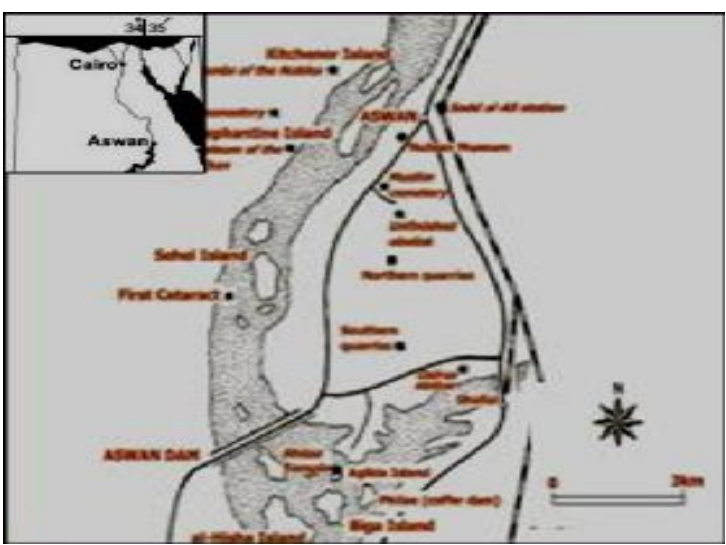

Fig.1 shows a modfied map of Aswan city

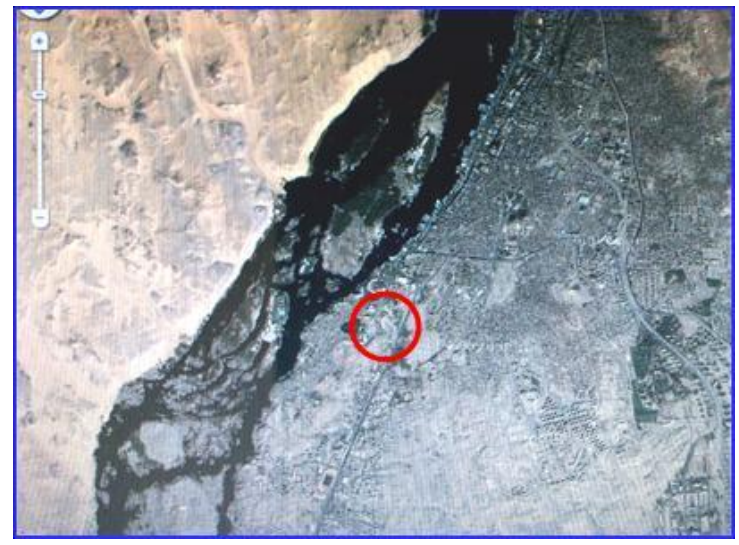
43,000 sq. m. have been planted with

palm trees, flowers, and climbing plants, spread over natural rocks [6]. An opendoor exhibit is planned for the garden. The open -door exhibition includes 90 rare monumental pieces of stone representing various ages, Pharaonic, Greco-Roman, Coptic and Islamic. The pathway around the site - along with other paved areas, sitting areas, etc...- is constructed from granite and sandstone paving and steps, and in addition to providing access around the site, also lead to the various artifacts composing the museum's open-door exhibition [7][8][9]. The aim of this paper is to highlight on the mentioned stone artifacts, to evaluate its current exhibition status for the long-term preservation. Recommendations for the improvement of out door artifacts exhibition in the Nubian museum can be established on the base of the present results.

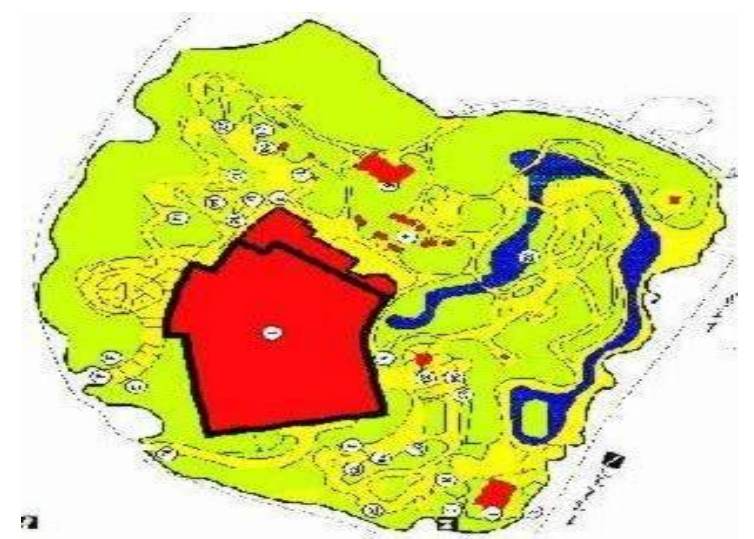

Fig.2 shows a modfied map of Aswan city

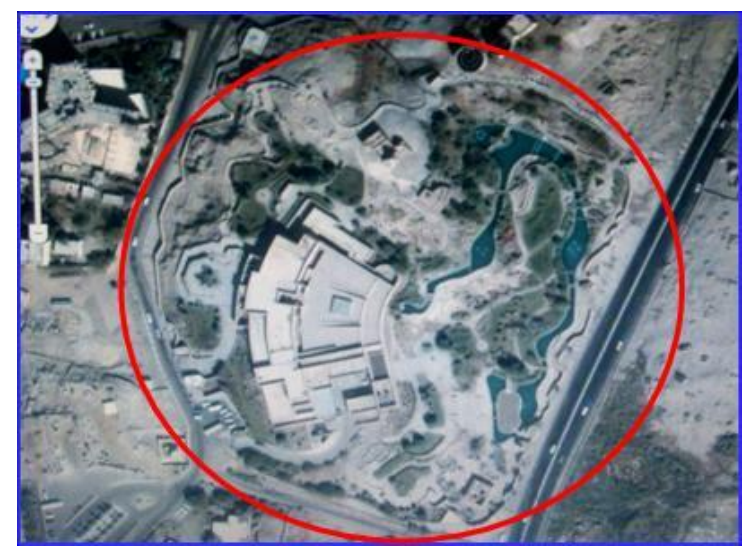

Fig. 3 Shows a satellite images shows the location of the Nubian museum 


\section{The artifacts exhibition status "aspects and factors of deterioration "}

The deterioration of materials depends on two factors: the nature of the material (Intrinsic factors) and the surrounded environment (Extrinsic factors), [10]. However, some degree of understanding can be gained by trying to identify the factors in the environment which may be affecting the deterioration of artifacts. Possible factors are very wide ranging and include earthquake, fire, flood, terrorism, vandalism, neglect, tourism, previous treatments, wind, rain, frost, temperature fluctuations, chemical attack, salt growth, pollution, and biodeterioration, and .... etc. These environmentally induced risks mostly occur simultaneously and co-exist in complex interrelationships in the deterioration process, [11] [12]. As a matter of fact values and fluctuations of temperature and relative humidity in the surrounding environment are one of the most important causes of deterioration.

\subsection{Air temperature variation}

The dominated average temperature at the study area is $26.75^{\circ} \mathrm{C}$. Where, $10.00^{\circ} \mathrm{C}$., is the lowest monthly average (occurring in January) while $42.00{ }^{\circ} \mathrm{C}$ is the highest monthly average (occurs in June). This gives us an average range of temperatures of $17.00^{\circ} \mathrm{C}$, tab. (1). These fluctuations in temperature and alternative cycles with relative humidity can cause various forms of damages and deterioration to museum collections. Temperature in the museum exhibition is the third important factor of deterioration, immediately after the humidity and pollution. The increase of temperature can cause a variety of reactions such as: $1^{\text {st }}$ the acceleration of the deterioration chemical process affecting the materials. $2^{\text {nd }}$ the acceleration of natural processes, such as the movement of water and air through stable particulates. Usually, $5^{\circ} \mathrm{C}$ raises can increase the rate of such processes from $100 \%$ to $130 \%$, [17] [18]. $3^{\text {rd }}$ the expansion of exhibits materials, where, the exhibited stone artifacts are
Which affect the behavior of the materials in general? Sudden changes and intense space variations of air temperature and relative humidity are supposed to induce stresses to several materials: this in turn creates cumulative and irreversible alterations of the physical and chemical properties which could accelerate the deterioration process, [13] [14] [15]. All The previous mentioned factors cause decay in two distinct ways: physical deterioration "the breakdown of structure of materials" and chemical deterioration" the alteration of the chemical composition of materials [16]. Furthermore, we have to put the man made damages into our consideration as a main factor of deterioration process. Through observing the museum garden, it could be seen that the exhibited stone artifacts are suffer from sever deterioration factors which could be summarized as follow:

considering a bad conductor of heat which has a different thermal expansion and contraction coefficient according to its mineralogical composition. Because of exposing the stone artifacts to the daily temperature fluctuation the surface is in expansion and its depth still in contraction which making a thermal shock of the stone artifact and vice versa by night. The results of that are the loosing of the cohesive among grains and fragmentation disintegration and exfoliation sometimes. $4^{\text {th }}$ the partial drying up of exhibits may result in raising the fragility level of these objects (crystallization of salts cycle) especially, if the humidity is not kept stable. Finally, the increase of temperature within museums can be caused by the (natural and artificial) illumination of objects. The illumination of objects can cause the drying up of exhibits, even though this drying is controlled and the humidity of the environment remains stable [12] [17] [18] [19]. 
Table (1) shows the Air temperature degrees variation in Aswan.

Months Jan. Feb. Mar. Apr. May. Jun. Jul. Aug. Sep. Oct. Nov. Dec.

\begin{tabular}{|c|c|c|c|c|c|c|c|c|c|c|c|c|}
\hline $\begin{array}{c}\text { Max. T. } \\
{ }^{\circ} \boldsymbol{C} .\end{array}$ & 37.8 & 39.2 & 43.4 & 48.1 & 48.3 & 50.6 & 48.4 & 48.3 & 48.2 & 46.4 & 41.8 & 37.0 \\
\hline $\begin{array}{c}\text { Min. T. } \\
{ }^{\circ} \boldsymbol{C} \text { C. }\end{array}$ & 1.6 & 1.7 & 5.4 & 7.5 & 13.6 & 18.2 & 20.2 & 19.8 & 15.8 & 11.8 & 6.5 & 4.0 \\
\hline
\end{tabular}

\subsection{Direct sunlight.}

It is well known that the deterioration process of materials requires energy. Light is the most powerful source of energy in museums . This energy has both electrical and magnetic properties, which is known as electromagnetic radiation [17]. The amount of energy that given off by a light source can be illustrated in the light spectrum, "Electromagnetic spectrum is divided into wavelengths of energy, which range from low (radio waves) to high (gamma rays). The range of wavelengths from light sources (daylight and artificial light) can be divided into three regions: ultraviolet radiation or UV (300$400 \mathrm{~nm})$, visible radiation $(400-760 \mathrm{~nm})$ and infrared radiation (over $760 \mathrm{~nm}$ ) [12]. We perceive IR as heat". It is another agent of deterioration that can cause damage to museum objects. Light causes fading "The absorbed energy can 2.2.1. Basic standards for exhibit light levels

Basic standards for exhibit light levels are 200 lux maximum for less light-sensitive objects including: tempera paintings and oxidize agents of deterioration and preservation pigments, altering their color and normally causing them to fade, darkening, yellowing, embrittlement, stiffening, and a host of other chemical" [16]. These are often enhanced by the presence of moisture and physical changes. Damage to artifacts and its effects are irreversible. The damage done by light depends on the intensity of the light and also on the distribution of the radiant energy over the visible spectrum. The shorter the wavelength of the light source, the more damaging to the surface of an object. Of special concern to museum collections is the high proportion of UV energy in normal daylight "sunlight". Daylight light in museums emits varying degrees of UV radiation. This radiation (natural light has the highest UV radiation rate) is the most damaging to museum artifacts [12]

Table 2: shows the basic standards for exhibit light levels according to the artifact material. (Modified after, NPS Museum Handbook, Part I (1999)

Light levels" Lux|”.

Artifacts.

Dyed organic materials ,textiles, watercolors, photographs

50 lux maximum for especially and blueprints, tapestries, prints and drawings, light- sensitive materials. manuscripts, leather, wallpapers, biological specimens, fur
300 lux for other materials that are not light-sensitive including stone, tab. (2) [12] [20] [21], and feathers.

200 lux maximum for less lightsensitive objects [21].

300 lux for other materials those are not light-sensitive.
Un-dyed organic materials, oil and tempera painting and finished wooden surfaces.

Metals, stone, ceramics and some glass. 


\subsubsection{Illuminance of sunlight.}

The sunlight illuminance is different during the day, which is 400 lux in sunrise or sunset on a clear day. On the other hand is 10,000-25,000 lux for Full daylight (not direct sun) and 32,000130,000 lux in direct sunlight, which is so high according to the basic standards for exhibit light levels for the tempera painting and the stone artifacts. From that data we can say the artifacts of the Nubian museum out door in general "especially the colored one" suffering from severe damage because of the very high and long

\subsection{Moisture and rainfall.}

It is well known that water plays such a major role in the chemical degradation chemistry of the artifacts. It is generally agreed that degradation processes will be speeded up by the presence of moisture [24]. On the other hand, rapid fluctuations in humidity can cause some forms of damages such as, cracking, splitting, expanding, or contracting. In Aswan, wet weather accumulates to give us a total average of $1.00 \mathrm{~mm}$ (0.04in) per year. Therefore the monthly average rainfall is $0.08 \mathrm{~mm}(0.00 \mathrm{in})$. May is the wettest month when an average of $1 \mathrm{~mm}$ (0.04in) of rain falls over a period of 1

\subsection{Man-made damages.}

The man made damages affecting the artifacts of out door Nubian museum includes the following items: $1^{\text {st }}$ using some types of unsuitable conservation material such as stone supports fixed with wooden beams covered with various mortars, in addition to using the corroded metallic mesh for this purpose. $2^{\text {nd }}$ inappropriate use of labels, which are fixed in inappropriate places as well, on the other hand some of the artifacts have not any labels. $3^{\text {rd }}$ the bad location selected for some artifacts "some of the artifacts are surrounded by a different kind of black wires through a very bad way of exhibition". $4^{\text {th }}$ the inappropriate Irrigation system: As the irrigation system by immersion was used to be employed, this affects negatively to the exposing to the sunlight illuminance [22].It can hit the stone artifacts surfaces and start the degradation processes which may be irreversible, such as cracks in the surface, or colour alterations and fading, or the transport of salts to the surface. Thus, for the best form of conservation, it becomes necessary to protect the artifacts especially those colored, from exposure to direct sunlight illuminance. This means knowing exactly when a monument is at risk and taking the necessary steps for the protection [23].

day while the rest of the year only $0 \mathrm{~mm}$ (0.00in) of rain falls. Aswan's climate enjoys an average of 1 day per year with greater than $0.1 \mathrm{~mm}(0.004 \mathrm{in})$ of rainfall. Relative humidity at Aswan averages $30.58333333 \%$ over the year. $20 \%$ is the lowest monthly average of relative humidity mostly which occurs in May and $46 \%$ is the highest monthly average relative humidity which occurs in December. Anyhow the main problem of moisture of the stone artifacts of the out door Nubian museum coming from the water irrigation system of the garden and sometimes from the rainfall.

museum stone artifacts. Accordingly to that, humidity rate has increased in its supports, on which the stone reliefs executed, that embodied in the saturation of the paved areas the site with the water of the Irrigation. The other result form of this irrigation system is the crystallization of salts on the lower parts of some of the artifacts. Previous treatment and the current conservation: different types of mortars used for completion, incompatible with the stone artifacts. On the other hand, most of the artifacts are covered with dense layers from dirt's, dust and different encrustations, together with some salts and bird excretes. As a result of, lack of conservation, those previous problems gradually aggregate, fig. $(4,5,6,7)$. 

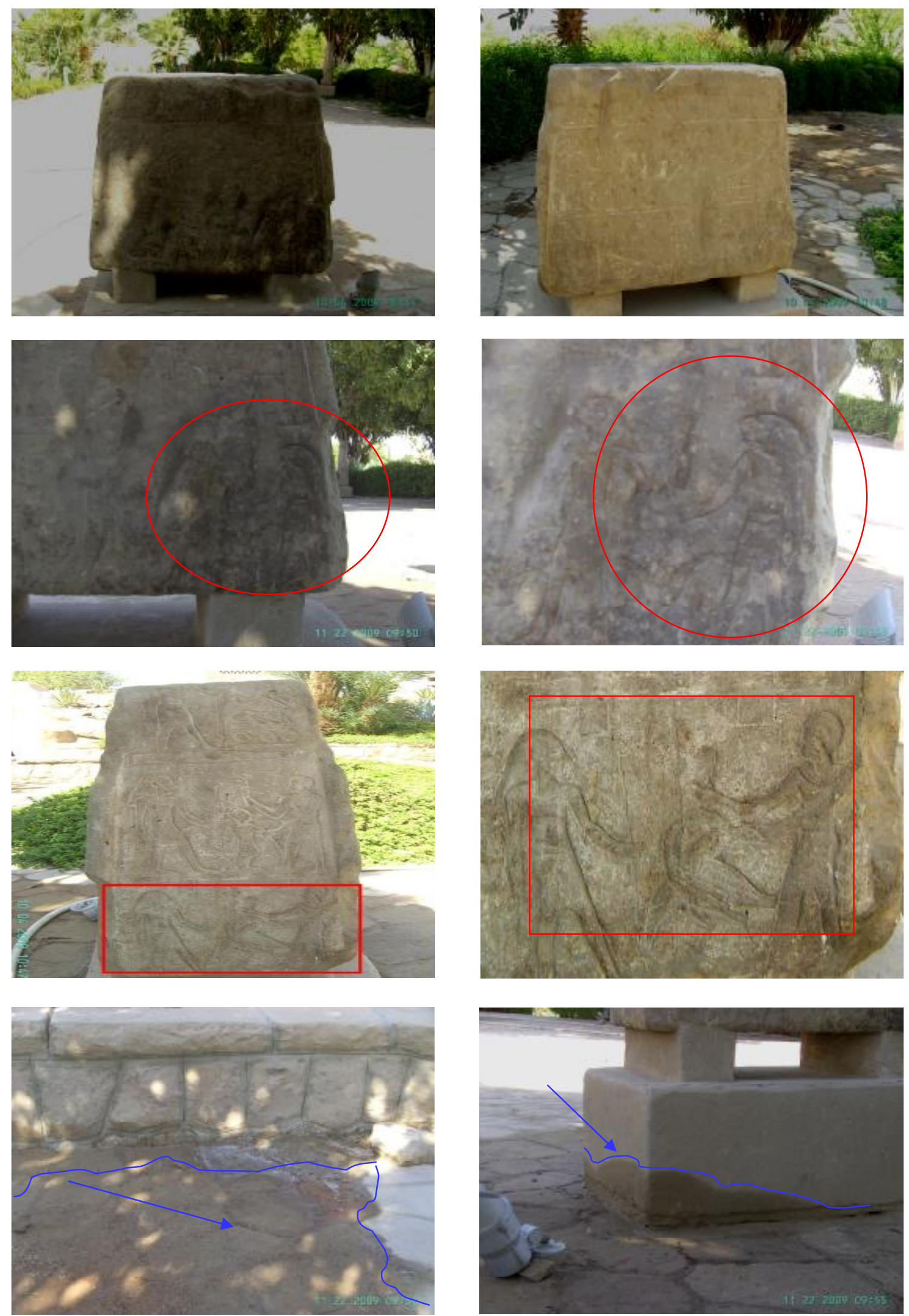

Fig.4 (a-h) Show a sandstone Stella without label, from all sides, engraved in a sunken colored relief suffering from severe damage which revealed in different deterioration aspects moisture from the garden irrigation, dirt's, dust, encrustations, crystallization of salt " as a result of rising moisture and bird excretes, Together with some deterioration of pigments, in the forms of disfiguring, fading, disintegration and locally missing. 

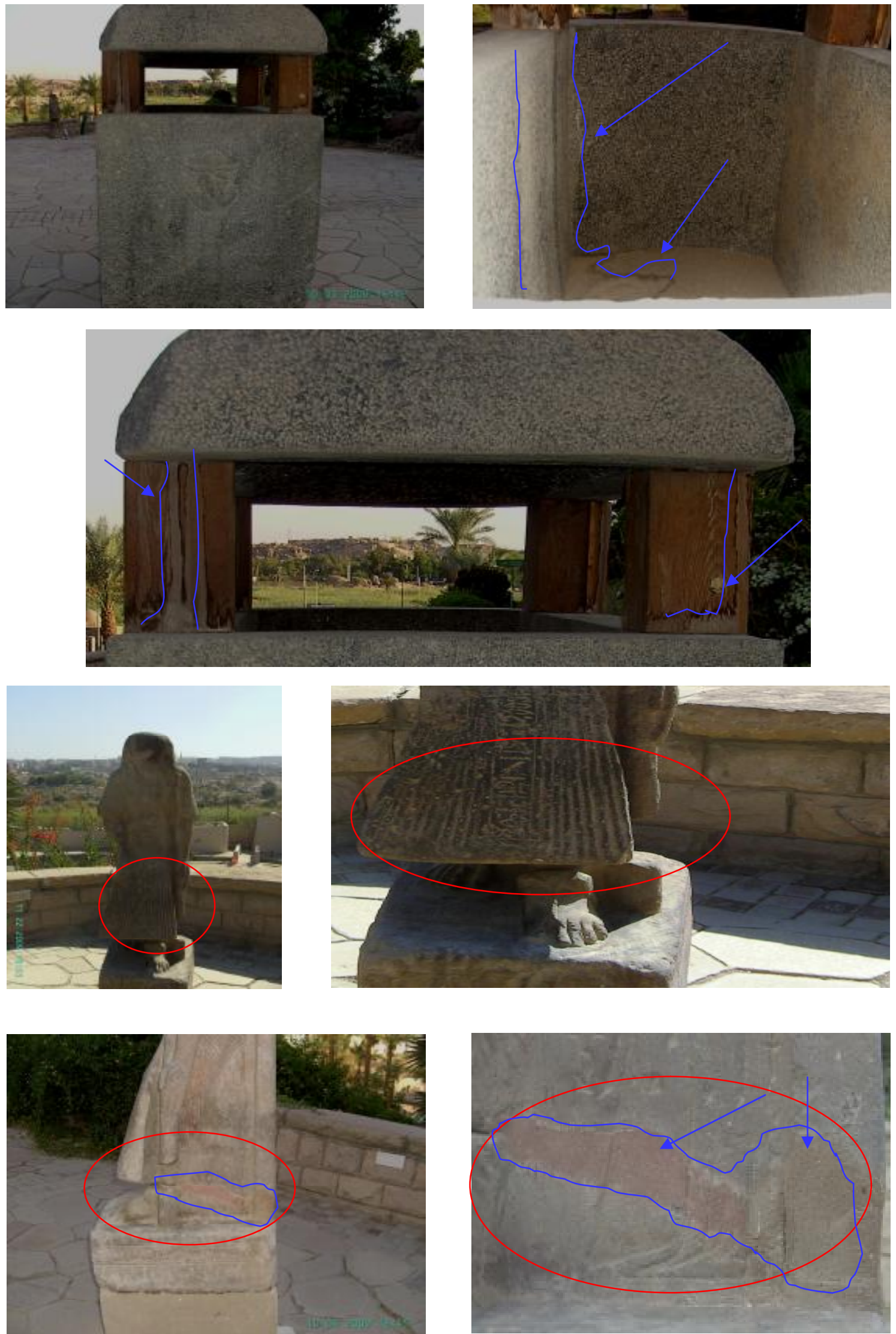

Fig.5 (a-g) Show a granite sarcophagus (a-c) and sandstone statue (d-g) suffering from severe damage which revealed in different deterioration aspects: dirt's, dust, encrustations, bird excretes and rainfall leaking (a-c) along with the improper completion works. 

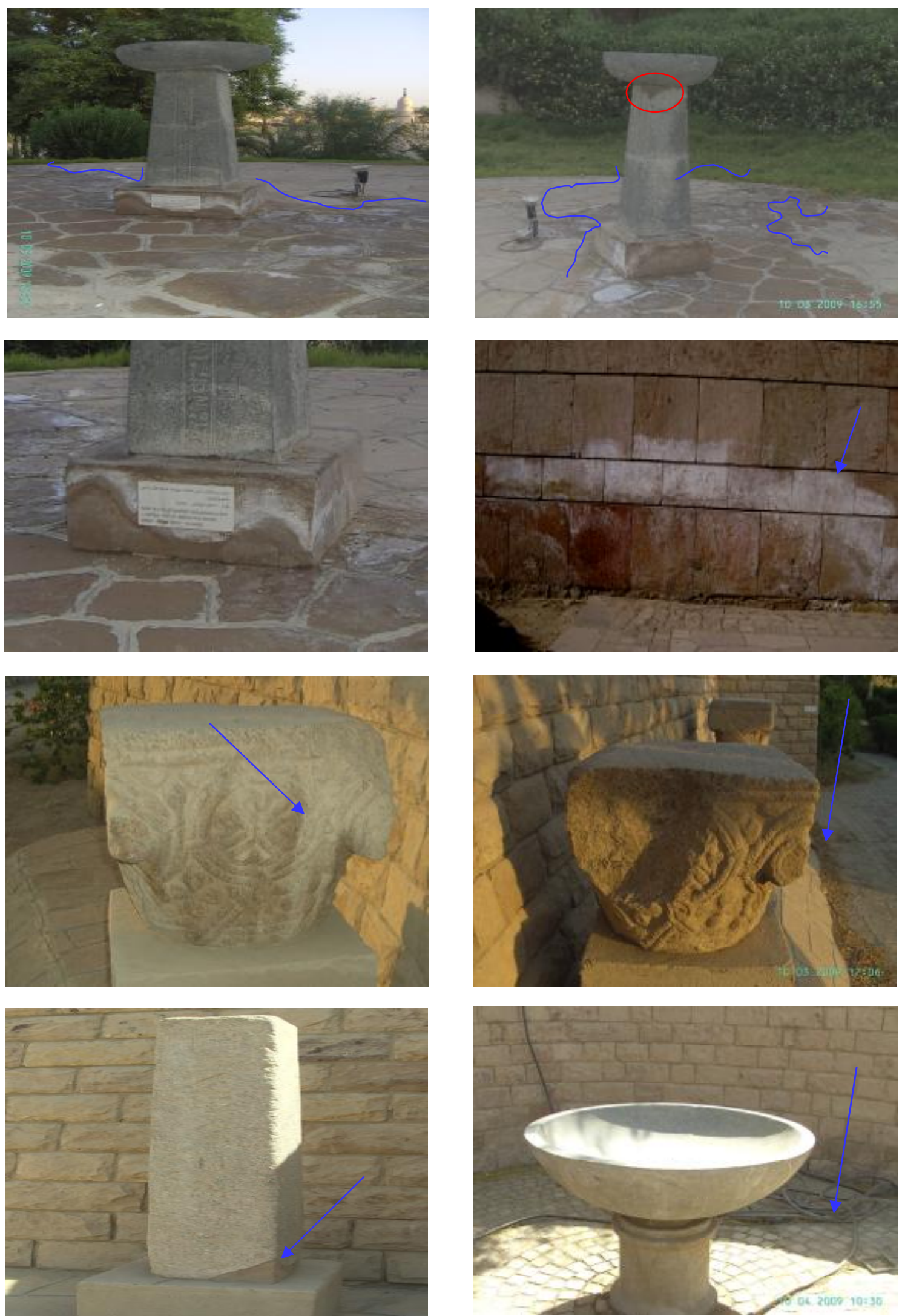

Fig.6 (a-g) Show some of the Nubian museum stone artifacts: a basalt basin on an engraved pillar shaped base (a-b), granite capital and obelisk (d-f) and a basalt basin ( $g$ ) .the artifacts are suffering from fluctuation of rainfall leaking and rising moisture "clearly seen on the form of crystallization of salts on the artifacts and the wall of the museum also", improper completion work along with dirt's dust,.. etc., are obviously observed as well. 

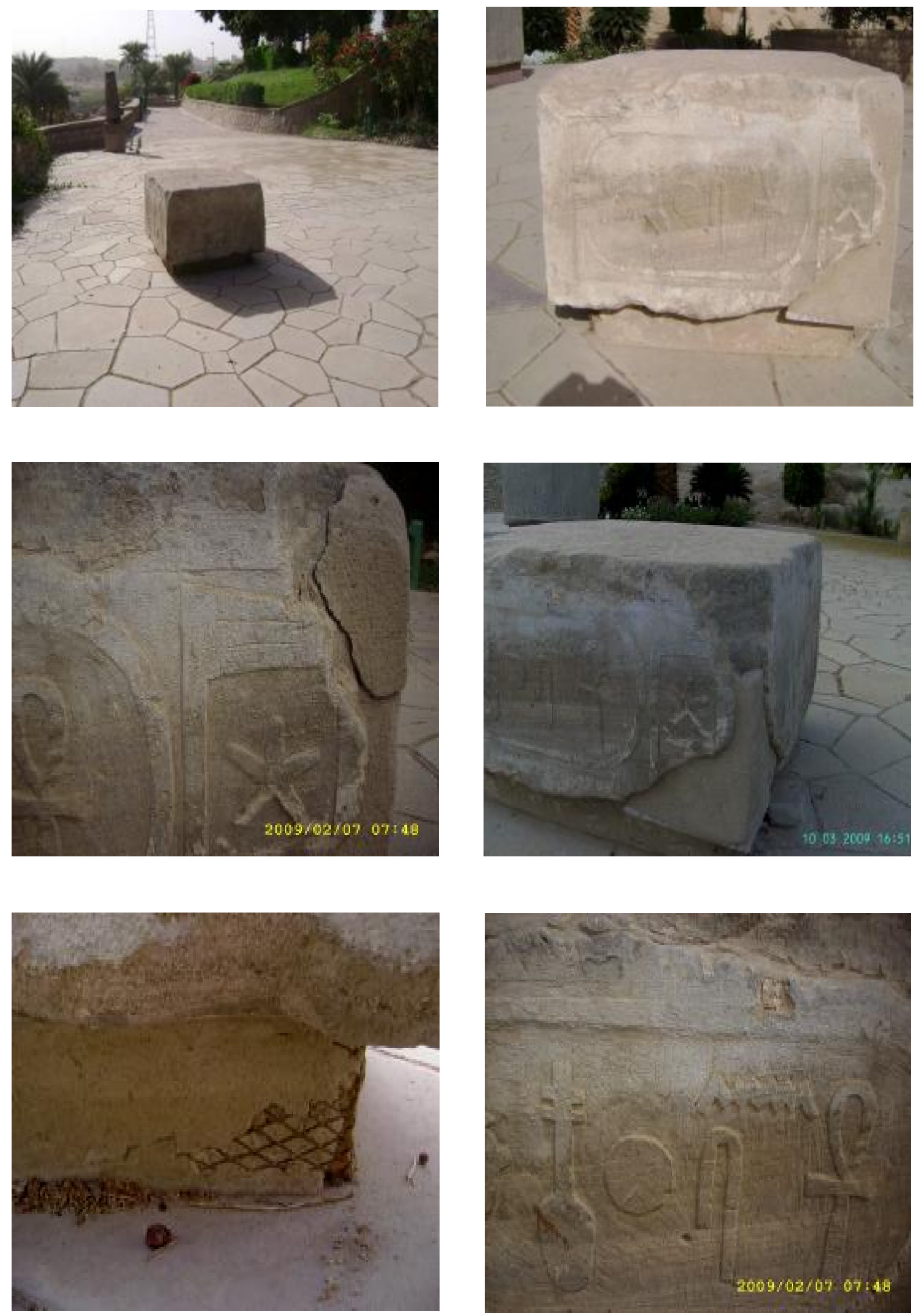

Fig.7 (a-f) Show base of a statue engraved for the king ANKH-S- NEFER-IB-RE from sandstone Aswan, it suffers from dense layers from excretes, dust, dirt's,....etc. severe damage of the base was also observed due to previous intervention work and what is called stone bleeding. In addition, improper completion work was observed, with using of corroded metallic mesh. 


\section{The case study:}

The case study is a stone relief Stella of Ramses the second engraved with hieroglyphic writings on one face and the titles of the king on the other face side. It is from sandstone, 19 dynasty elephantine. Its dimensions are about $90 \times 80 \mathrm{~cm}$. It suffers from many deterioration factors that embodies in different aspects like dirt's, dust, encrustations, salt crystallization "as a result of rising dampness", and bird excreting, together with some deterioration of pigments, in the forms of disfiguring, fading, disintegration and missing. Beside that, degradation of the artificial base of the Stella, which covered with deteriorated wooden beams, was clearly seen, fig $(8,9)$.
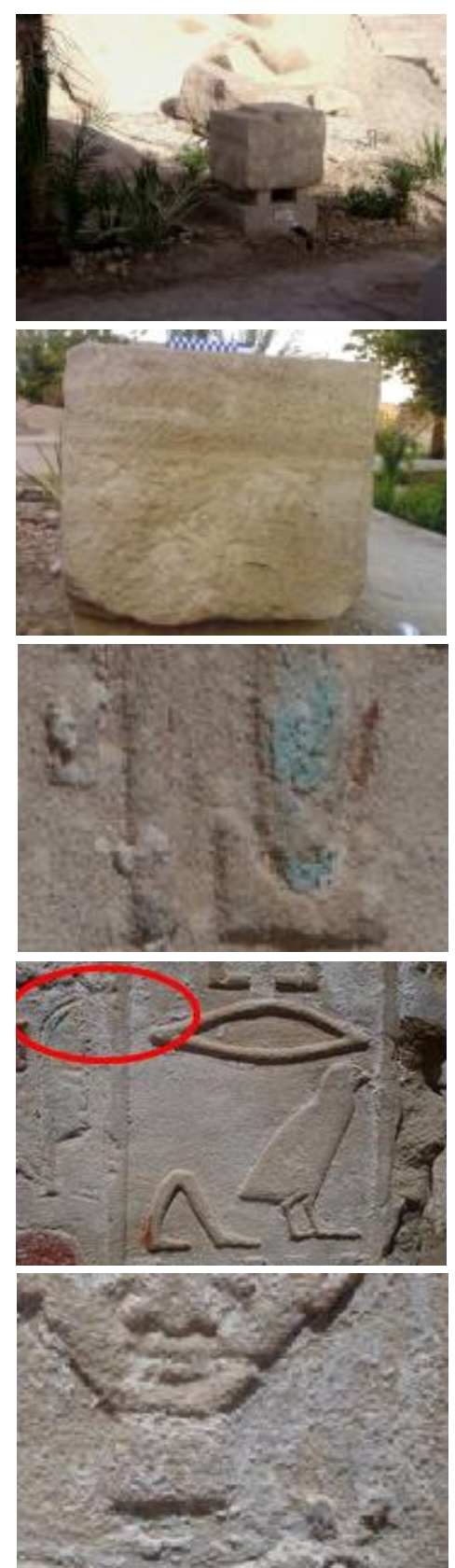
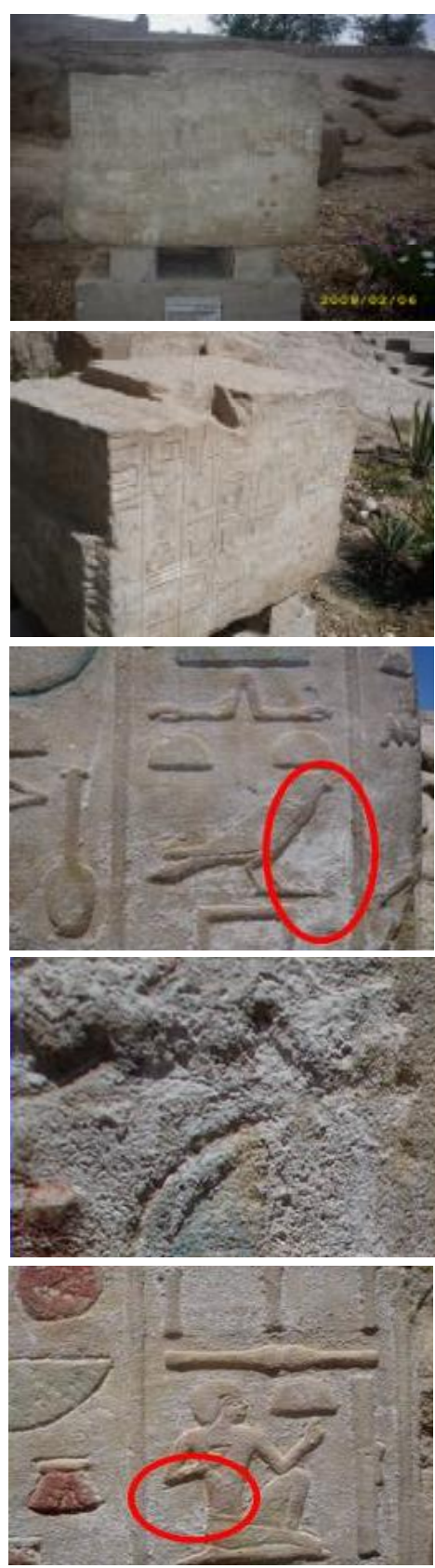
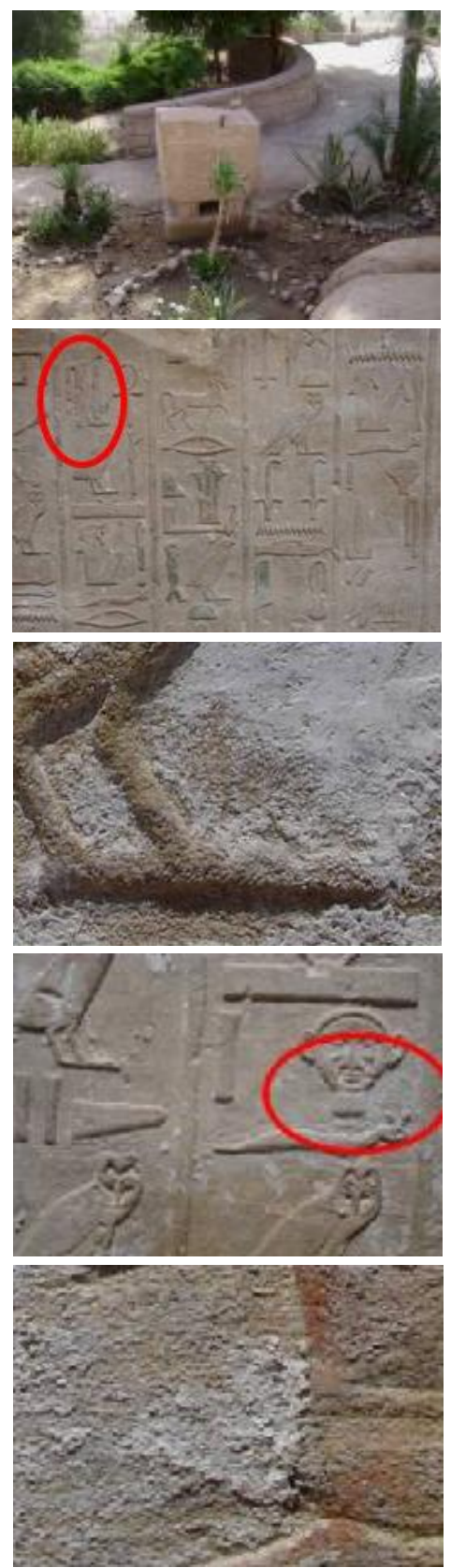

Fig.8 (a-o) Show the colored relief sandstone stella "case study" suffering from different deterioration aspects revealed in : dirt's, dust, encrustations, crystallization of salt " as a result of rising dampness", bird excretes and deterioration of pigments, in the forms of disfiguring, fading, disintegration and missing. Beside that, degradation of the artificial base of the Stella, which covered with deteriorated wooden beams, was clearly seen. 

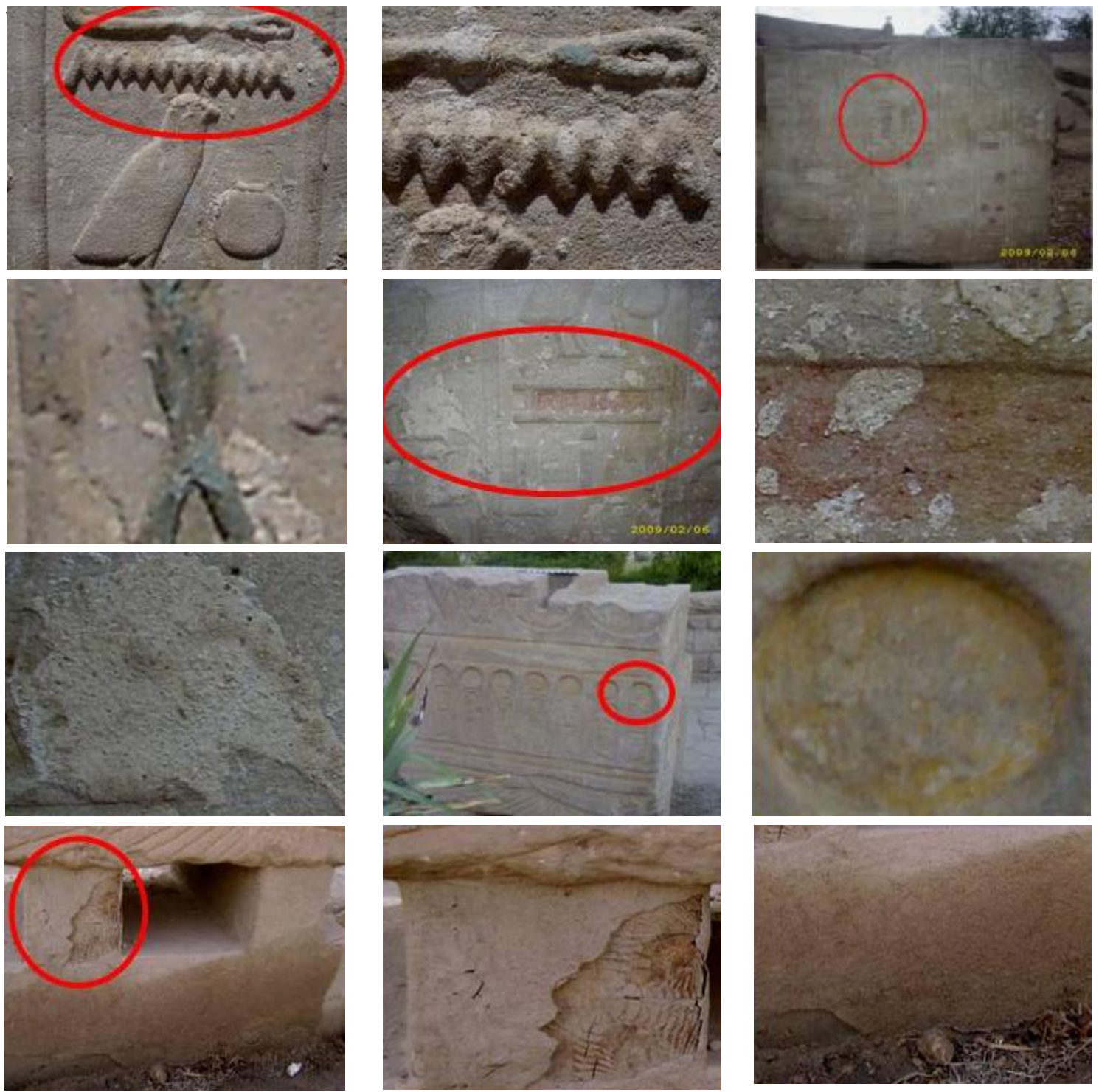

Fig.9 (a-l) Show the same colored relief sandstone Stella "the case study " suffering from different aspects of deterioration in details" notice the deteriorated wooden beams".

\section{Materials and methods:}

The samples taken from the stone Stella were collected for investigation and analyses. They were taken from several aspects of deterioration (salts and incrustation) and the blue pigment (it was too difficult to take the samples.), the following methods and techniques were used - X-Ray Diffraction (XRD), a Phillips X-ray diffraction equipment model pw/1840 with $\mathrm{Ni}$ filter, $\mathrm{Cu}$ radiation $1.54056 \mathrm{~A}^{\circ}$ at $40 \mathrm{KV}, 25 \mathrm{~mA}$, $0.05 / \mathrm{sec}$. Scanning Electron Microscope (SEM EDAX), photographs and microanalyses were carried out by

utilizing S.E.M. Philips XL 30 attached with EDAX unit, with accelerating voltage $30 \mathrm{~K} . \mathrm{V}$., magnification $10 \mathrm{X}$ up to $400.000 \mathrm{X}$ and resolution for $\mathrm{W}$. (3.5nm). The sample coated with carbon for investigation and analyses. Light Optical Microscope (L.O.M.), LOM Zeiss standard microscope was used to investigate surface samples from the blue pigment and the sandstone Stella. Fourier transform infrared spectroscopy (FTIR) Fourier transform infrared spectroscopy (FTIR) was used for studying small sample of blue pigment. 


\section{Results and discussion:}

\subsection{X-Ray Diffraction (XRD)}

XRD was carried out to identify the different crystalline phases present in the studied samples. The results obtained by $\mathrm{x}$ - ray diffraction analysis of the studied samples shows that, the sample which represents the salt (the sample was taken from the crystalline salt on the Stella surface) consists of halite $\mathrm{NaCl}(05-0628)$ mineral as the only component of the sample". Fig. (10) provide a summary of the results obtained". It is well known that halite is soluble and hygroscopic salt. On the other hand anhydrite $\mathrm{CaSO}_{4}$ (06-0226) mineral was the main component of the incrustation layer as a deterioration aspect on the surface of the Stella. The behavior of salts may seem unpredictable since they can remain inert for long periods and then suddenly become active causing natural erosion, disfiguring and weakening the surfaces on a microscopic level by a progressive action. Salt damage is largely attributable to two mechanisms: crystallization of salts from solution and hydration of salts that can exist in more

\subsection{Scanning Electron Microscope}

Scanning electron microscopy was carried out on the blue pigment "the main pigment in the Stella" which was covered by a thick layer of dirt's. The deteriorated surface and the fresh layer of the pigment were studied. The result of the blue pigment surface revealed the presence of $\mathrm{Ca}$ and $\mathrm{S}$ as a major elements and $\mathrm{Si}, \mathrm{Al}, \mathrm{Cu}, \mathrm{Mg}, \mathrm{Fe}$, as a minor elements, indicating to the presence of calcium sulfate with some other impurities as a deterioration aspect covering the deteriorated Egyptian blue pigment, fig. (11 a, b, c). Those results confirm the in situ visual observation of the status. On the other hand the microanalyses of the fresh layer of the blue pigment revealed the presence of $\mathrm{Ca}, \mathrm{S}, \mathrm{Cu}$ and $\mathrm{Si}$ as a major elements confirming using of the Egyptian blue pigment as well, fig. (12 a, b, c). Egyptian Blue is consider as one of the than one hydration state. Thermal expansion of the salts is a third less important factor. The growth of salt crystals within pores can cause stresses "there is a great increase in volume", which are sufficient to overcome the stone's tensile strength. When the migration of the soluble salt, to the surface of the stone is faster than the rate of drying, the crystals deposit on the top of the external surface and form visible efflorescence. When the migration is slower than the drying rate, the solute crystallizes within the pores, at varying depth, causing crumbling and powdering of the stone. On the other hand, insoluble salts may precipitate over the surface of objects, obscuring them completely .The problem will be more effective with the colored artifacts. In fact, it is known that much damage to porous materials is caused by the mechanical stresses induced by the crystallization/hydration solubilisation cycles of salts into the porous matrix [14] [16] [25] [26] [27].

\section{(SEM)}

oldest synthetic color pigments which had been used during all the ancient Egyptian ages in Egyptian history "it was used at least for 3000 years as a precious pigment, spreading in the whole Roman Empire" . Egyptian Blue or blue frit, a calcium-copper tetra silicate with the formula $\mathrm{CaCuSi}_{4} \mathrm{O}_{10}$, a multicomponent synthetic blue pigment has been recorded in ancient Egypt since the fourth dynasty of the old Kingdom $(26002480 \quad$ B.C. $)$. The pigment consisting of cuprorivaite $\left(\mathrm{CaCuSi}_{4} \mathrm{O}_{10}\right)$ with variable amounts of wollastonite $\left(\mathrm{CaSiO}_{3}\right), \mathrm{Cu}$-rich glass and cuprite $\left(\mathrm{Cu}_{2} \mathrm{O}\right)$ or tenorite $(\mathrm{CuO})$ was prepared by melting the copper-rich ingredient with lime and desert sand. Low melting temperatures (below $742 \sim$ were achieved by addition of flux-like plant ashes. The high quality of the pigments Collected from monuments of the fifth 
dynasty (2480-2320 B.C.) may indicate that the first manufacture was in early dynastic or perhaps predynastic eras. During the reign of Thutmosis III $\left(18^{\text {th }}\right.$ dynasty, 1490-1436 B.C.) probably

\subsection{Light Optical microscope (L.O.M.)}

Two samples from the colored blue pigment and the sandstone from the studied colored relief were investigated by LOM. The results shows the severe damage "fading" of the Egyptian Blue pigment dues to the long of and highly exposing to the deterioration factors, especially the illuminance of sunlight. The observed fading was so clear comparing

\subsection{Infrared (FT-IR)}

FTIR was carried out to a sample from the blue pigment. Few milligrams of the sample were diluted in $\mathrm{KBr}$ and the powder mixture was crushed in a mechanical die press to form a translucent pellet. Before describing the results obtained, three observations should be made: first, since the in each painting is extremely small, the interpretation of the results of FTIR analysis is very complex. Second, this organic material is inevitably greatly deteriorated; it is well known that, in the course of time, the many and varied environmental aggressions are conducive to deterioration [32][33][34][35]. Third, the presence of calcium sulphate as an

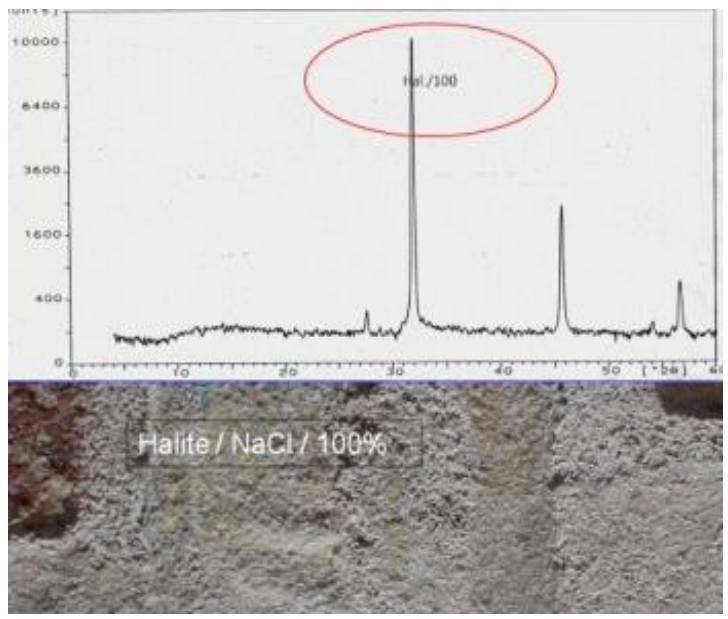
percentage of organic material existing

bronze filings were first applied as starting material, thus indicating a technological innovation. This new method was employed till the Roman times [28][29][30][31].

with a raw sample of the Egyptian blue, fig. $(13)(14)$. On the other hand the investigation of the stone sample showed the surface deterioration of the colored relief Stella by accumulation of different kind of dirties and loosing of cohesion among the grain of the stone" the matrix.

aspect of deterioration is reflected in an important band in the IR spectrum, caused by sulphate groups. This strong band could be overlapping others which are precisely the interval where the absorption of some characteristic functional groups occurs that would unquestionably contribute to a greater understanding of the nature of the existing organic medium. The result of the studied sample indicating to there is no evidence of any protein as a binder for the pigment "indicating to the severe damage of the pigments" and calcium sulphate groups and silicates were so clear in the sample representing the aspect of deterioration in the analyzed deteriorated blue pigment sample, fig. (15).

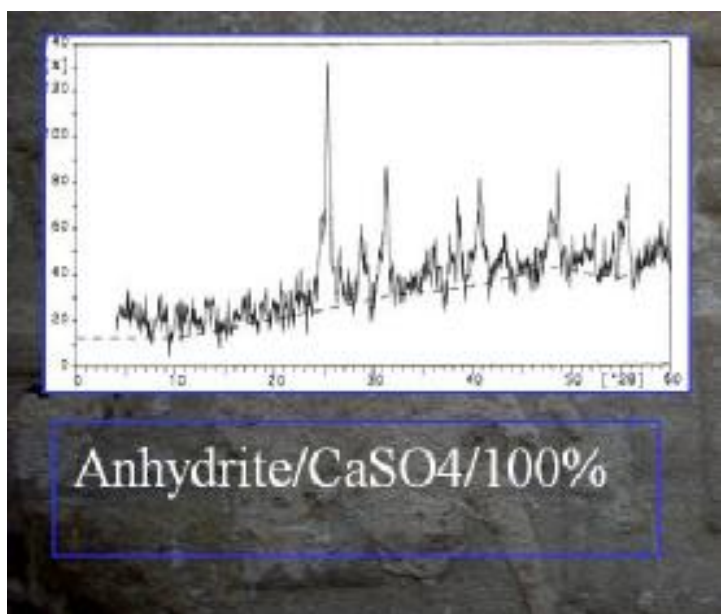

Fig.10 Shows XRD patterns for the salt and the encrustation samples and the mineralogical composition. 

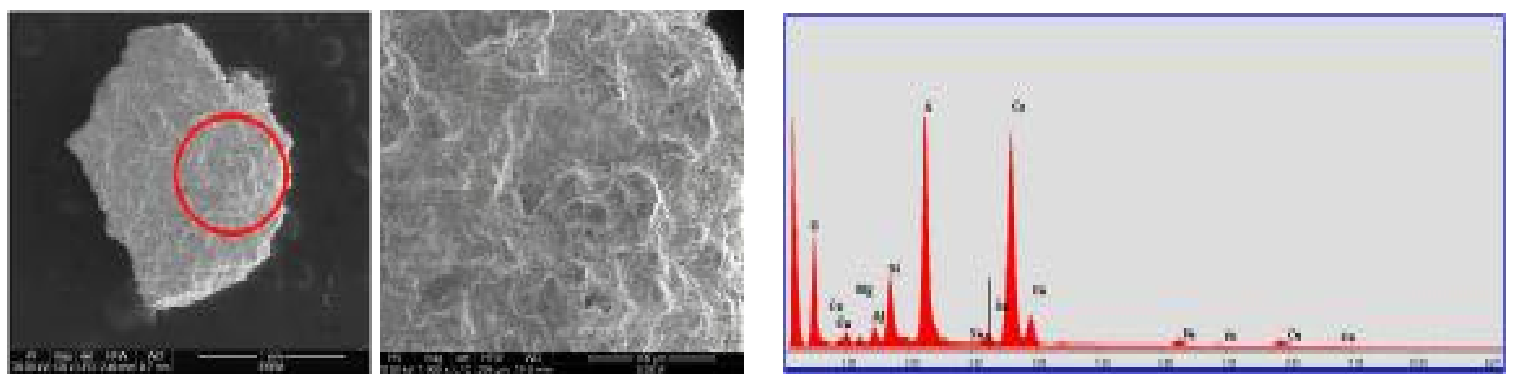

Fig.11 $(a, b, c)$ Show SEM (EDAX) microanalyses and photomicrograph of the surface of the blue revealed the presence of $\mathrm{Ca}, \mathrm{S}$ as a major elements and $\mathrm{Si}, \mathrm{Al}, \mathrm{Cu}, \mathrm{Mg}, \mathrm{Fe}$, as a minor elements, indicating to the presence of calcium sulfate with some other impurities as a deterioration aspect covering the deteriorated Egyptian blue pigment,
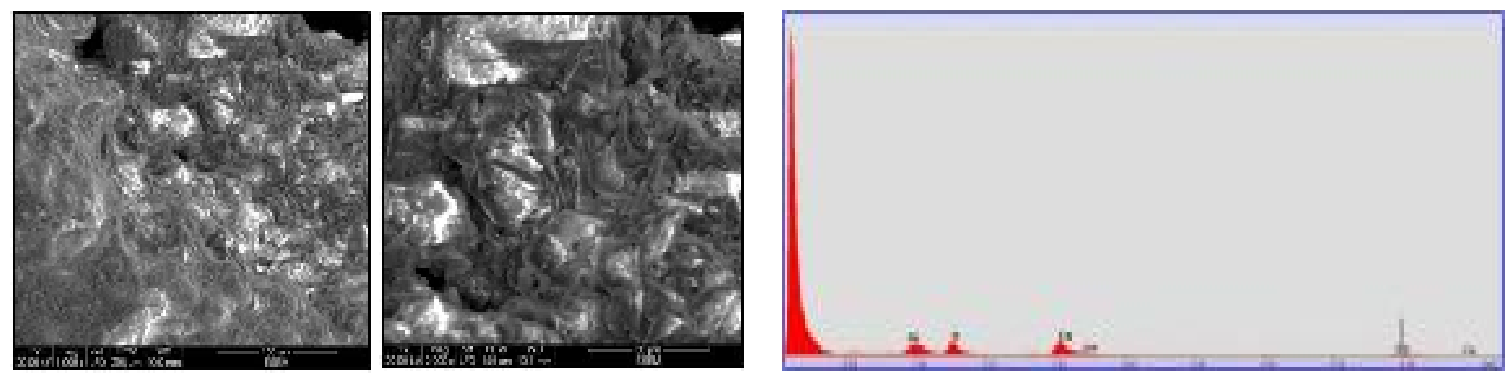

Fig.12 (a, b, c) Show SEM (EDAX) microanalyses and photomicrograph of the fresh layer of the blue pigment revealed the presence of $\mathrm{Ca}, \mathrm{S}, \mathrm{Cu}$ and $\mathrm{Si}$ as a major elements indicating and confirming using the Egyptian blue pigment as well.
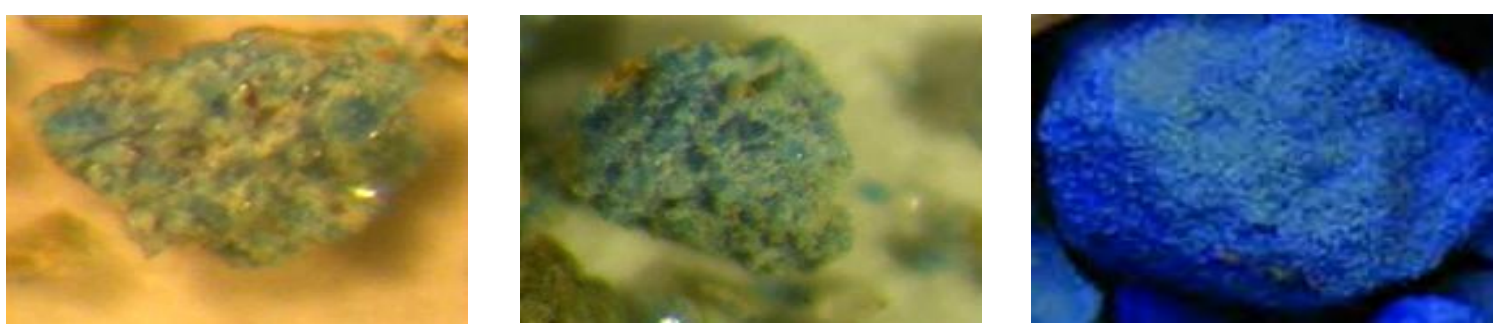

Fig.13 (a, b, c) Show LOM shows the deteriorated grains of the faded and detriorated Egyptian blue pigment comparing with afresh raw sample, magnification. X150- 160.
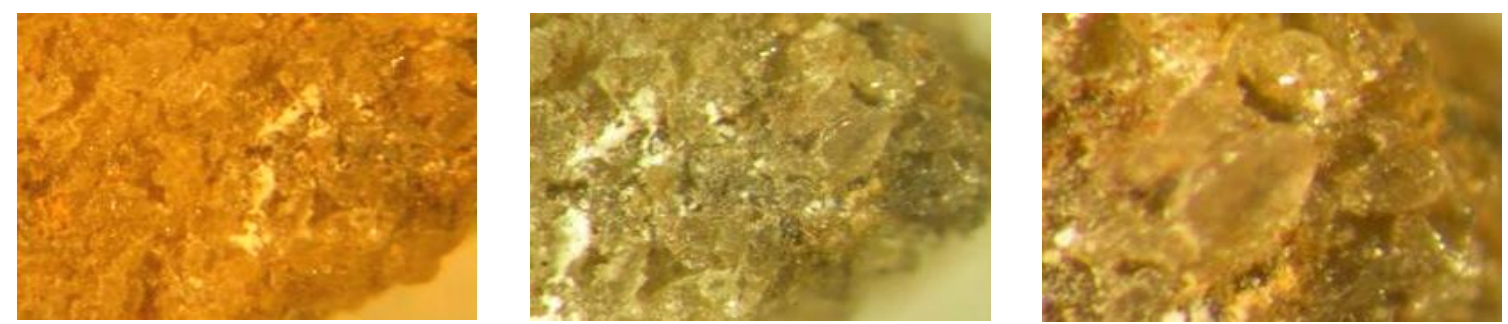

Fig.14 (a, b, c) Show LOM sample of the sandstone stella, shows the deteriorated surface of the colored stella" notice the cement losing among the quartz grains and the dirt's accumulation magnification. X150- 160.

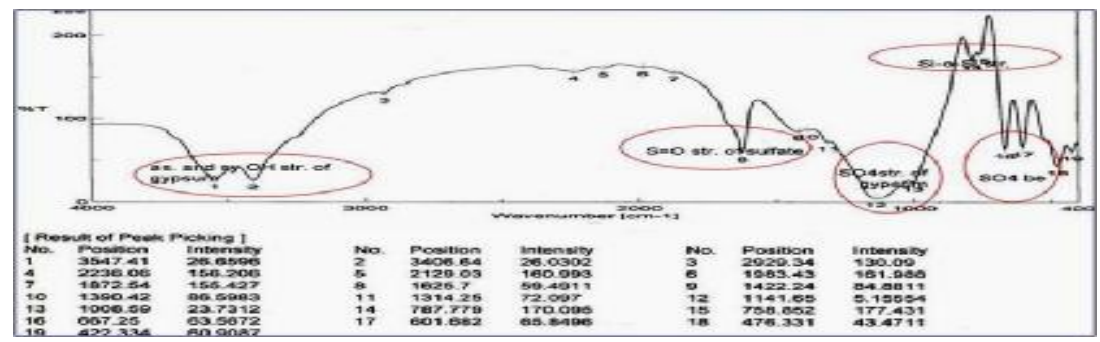

Fig.15 Shows FTIR Spectrum of the binding media for the studied sample. 


\section{Recommendations:}

The recommendations based on this study of evaluation of the studied artifacts are as follows - Display areas near water sources, for the stone artifacts in the Nubian museum out- door, should avoid. The necessity of changing the current irrigation system by immersing with another appropriate system. -Transferring the colored stone relief's artifacts to the indoor museum, avoiding its detrimental exposure to direct sunlight air temperature and humidity variations. -The necessity of removing the previous deteriorated and inappropriate interventions carefully and making completion works according to the international code of ethics and code of practices for the previous treated and the deteriorated artifacts. -The necessity of using waterproof labels for the entire out door artifacts in the Nubian museum. -The necessity of replacing the wooden supported beams by the steel ones. -The necessity of periodical conservation of the stone artifacts in the Nubian museum garden "regular maintenance". -Using appropriate shelters; if the display is outdoors, we will have more trouble avoiding natural light. Large objects can be placed in shaded areas or under a built shelter, but the amount and direction of light to which they are subjected will change as the day progresses. We will need to make sure that any outdoor signage is fade resistant

\section{Conclusion}

According to the study of the article results, some scientific points could be concluded as follows:-

The Nubian Museum in Aswan is the one of most recent museum that has been built with the cooperation between UNESCO and the Egyptian government. The open -door exhibition includes 90 rare monumental pieces of stone representing various ages, Pharaonic, GrecoRoman, Coptic and Islamic. Through observing the museum garden, it could be seen that the exhibited stone artifacts are suffer from severe deterioration factors. Rapid fluctuations in humidity, "Moisture and rainfall" cause different forms of damages on the open-door museum artifacts. On the other hand temperature variation in the museum exhibition is the one of important factor of deterioration, immediately after the humidity and pollution. Natural light, which has the highest UV radiation rate, is the most damaging to the painted museum artifacts. The man made damages also affecting the artifacts. The sandstone Stella of Ramses the second" the case study" suffers from many deterioration factors embodies in different aspects " dirt's, dust, encrustations, salt crystallization and bird excreting, together with some deterioration of pigments, in the forms of disfiguring, fading, disintegration and missing....etc. The investigated and analyzed samples of the stone Stella revealed, halite $\mathrm{NaCl}$ (05-0628) mineral as the only component of the salt sample "soluble and hygroscopic salt". On the other hand anhydrite CaSO4 (06-0226) mineral was the main component of the incrustation layer on the Stella surface. Calcium sulfate with some other impurities as a deterioration aspect covering the deteriorated Egyptian blue pigment, confirming the in situ visual observation. On the other hand the microanalyses of the fresh layer of the blue pigment revealed the presence of $\mathrm{Ca}, \mathrm{S}, \mathrm{Cu}$ and Si confirming using of the Egyptian blue pigment as well. The investigation shows the severe damage "fading" of the Egyptian blue pigment dues to the long of and highly exposing to the deterioration factors, especially the illuminance of sunlight...etc. The analyses of the pigments indicating to there is no evidence of any protein as a binder for the pigment " severe damage of the pigments" and calcium sulphate groups and silicates were so clear in the sample representing the aspect of deterioration in the analyzed deteriorated blue pigment. The most important recommendations based on this study are as follow:

- Avoid display areas for the stone artifacts near water sources.

- Changing the current irrigation system with another appropriate system.

- Transferring the colored stone relief's artifacts to the indoor.

- Removing the previous interventions carefully and start treatment according to the international code of ethics and code of practices. 


\section{References}

[1] Erman, A. and Grapow, H., (1971) Worterbuch der Aegyptin chem sprache, IV, Berlin, 69

[2] Magi, G., (1996) Aswan Philae Abu Simpel, caza editrice bonechifiernze-Italia.

[3] Brania A.A., (2001) Comparative study of treatment and conservation of Rock-cut Tombs of Elephantine Nobles, (Qubbet ElHawa) at Aswan with application on one of the selected tombs, Ph.D. thesis, Cairo University, Faculty of Archaeology, Egypt, pp. $1,2,105$

[4] http://www.egyptologyonline.com/aswan.htm., Map of Aswan, opened in 19/11/2009

[5] http://www.maplandia.com/egypt/upper.../ aswan /aswan/, Aswan/ Google Satellite Maps opened in 12/2/2010

[6]http://www touregypt.net/nubianm71.htm., Nubian museum outdoor area, opened in 2/10/ 2009

[7] http://www.touregypt.net/nubiamuseum.htm., The Nubian museum, opened in 2/10/2009

[8] http://www .numibia.net/nubia/intro.htm., Nubian museum, opened in 2/10/2009.

[9] http://shazlyasmail.tripod.com/photo.htm., Nubian museum, opened in 2/10/2009 .

[10] Price C. A., (1996) Stone conservation an overview of current research, The J. Paul Getty institute, Los Angeles, p.4

[11] Dardes k., (1998) The conservation assessment: a proposed model for evaluating museum environmental management needs, GCI, p.2

[12] NPS (1999) Museum collections environment in: Museum Handbook, Part I, pp.4-34

[13] Stefano P. C., Valentina F., and Marco F., (2009) A methodology for microclimatic quality evaluation in museums: Application to a temporary exhibit building and environment 44, pp.1253-1260

[14] Van Grieken R., Delalieux F. and Gysels K., (1998) Cultural heritage and the environment IUPAC, Pure \& Applied Chemistry 70, pp. 2327-2331

[15] Elovitz K.M., (1999) Understanding what humidity does and why, ASHRAE Journal, 41 (4). pp. 84-90

[16] Cronyn J.M., (2004) The elements of archaeological conservation J.M.Cronyn Taylor \& Francis eLibrary, pp. 23, 36-37

[17] Pavlogeorgatos G. (2003) Environmental parameters in museums building and environment 38, Elsevier, pp. 1457 - 1462

[18] Halsey, D.P., Dewis S. J., Mitchelle D. J., and Harris F. C., (1996) Influence of aspect upon sandstone weathering: The role of climatic cycles in flaking and scaling, $8^{\text {th }}$ international congress on deterioration and conservation of stone, Berlin, p.852

[19] Barros, L. A., (2002) Modes and mechanisms of rock weathering in: protection and conservation of the cultural heritage of the Mediterranean cities: $5^{\text {th }}$ symposium on the conservation of monuments in Mediterranean basin, deSeville, E.Galan, F.Zezza, eds, A.A Balkema, pp.3-6

[20] Camuffo D., (1998) Microclimate for cultural heritage, Amsterdam, Elsevier.

[21] Thomson, g., (1985) The museum environment, $2^{\text {nd }}$ edition, the national gallery, London, p. 23

[22] http://www. Wikipedia, the free encyclopedia.htm, Lux , opened in 29/11/2009.

[23] Bernardi A. and Vincenzi S., (1994) Diurnal Variation of Solar Radiation on differently orientated surfaces of monuments, IL NUOV0 CIMENT0 17 C, N. 4, pp. 431- 442

[24] Feller, R. L. (1994) Accelerated aging: photochemical and thermal aspects the Getty conservation institute, The J. Paul Getty institute, Los Angeles, p.115 
[25] Scilla G. , Emiliano C., Paolo P., Fabrizio I. , Piero B. , Luigi D., (2007) The conservation of the Vecchietta's wall paintings in the old Sacristy of Santa Maria della Scala in Siena: The use of nanotechnological cleaning agents, Journal of Cultural Heritage, 8, pp.119-125

[26] Cherer G.W., (2000) Stress from crystallization of salt in pores, in: proceeding of the $9^{\text {th }}$ International congress on deterioration and conservation of stone, Venice, Elsevier, Amsterdam pp.187-194

[27] Arnold A. and Zehnder K., (1990) Salt weathering on monuments, $1^{\text {st }}$ International symposium, the Conservation of monuments in the Mediterranean basin: the influence of coastal environment and salt spray on limestone and marble, Bari, pp. 31-54

[28] Jaksch H., Seipel W., Weiner K.L. and E1 Goresy A., (1983): Egyptian blue- cuprorivaite a window to ancient Egyptian technology, Naturwissenschaften Springer-Verlag ,70, pp. 525-535

[29] Uda M. , Nakamura M, Yoshimura S, Kondo J, Saito M. ,Shirai Y., S. Hasegawa, Y. Baba, K. Ikeda, Y. Ban, A. Matsuo, M. Tamada, Sunaga H, Oshio H, Yamashita D., Nakajima Y, and Utaka T., (2002) " Amarna blue" painted on ancient Egyptian pottery Nuclear Instruments and Methods in
Physics Research B 189, pp.382386.

[30] Emilio F. O., Agnoli F., and Mazzocchin G.A. (2006) An EPR study on ancient and newly synthesized Egyptian blue, Talanta 68, pp. 831-835

[31] Barnett J.R., Miller S., Pearce E., (2006) Colour and art: A brief history of pigments, Optics \& Laser Technology 38, pp. 445-453.

[32] Ruth S., (2006) Pigments and painting techniques of roman artists, focus magazine Issue 2, $\mathrm{p}$. 20.

[33] Eloisa M, Ana G. B, Antonio Gonzalez C, Monsalud O., (2000) Mortars, pigments and binding media of wall paintings in the 'Carrera del Darro' in Granada, Spain, Journal of Cultural Heritage 1, pp.19-28.

[34] Bersani, D., Lottici P. P. Antonioli G., Campani E., Casoli A., and Violante C., (2004) Pigments and binders in the wall paintings of Santa Maria della Steccata in Parma (Italy): the ultimate technique of Parmigianino, J. Ra Spec. 35, pp. 694-703.

[35] Casadio F., Colombo C., Sansonetti A., Toniolo L. and Perla Colombini M., (2005) Polychromy on stone bas-reliefs: the case of the basilica of Saint-Ambrogio in Milan, Journal of Cultural Heritage 6, pp.79-88. 